\title{
Develop and implementation of PC based controller for humanoid robot using digital potentiometer
}

\author{
Hairol Nizam Mohd Shah', Mohd Fairus Abdollah², Zalina Kamis ${ }^{3}$, Mohd Shahrieel Mohd Aras ${ }^{4}$, \\ Mohd Rizuan Baharon', Muhammad Zakwan Akmal Sallehoddin ${ }^{6}$ \\ ${ }^{1,2,3,4,6}$ Center for Robotics and Industrial Automation, Faculty of Electrical Engineering, \\ Universiti Teknikal Malaysia Melaka, Malaysia \\ ${ }^{5}$ Department of Computer System and Communication, Faculty of Communication and Information Technology, \\ Universiti Teknikal Malaysia Melaka, Malaysia
}

\begin{tabular}{|c|c|}
\hline Article Info & ABSTRACT \\
\hline Article history: & This paper introduced to develop and implementation of PC based controller \\
\hline Received Jan 3, 2019 & for humanoid robot using digital potentiometer. The main objective in this \\
\hline Revised Feb 13, 2019 & potentiometer circuit board that be able to control the humanoid robot \\
\hline Accepted Mar 10, 2019 & $\begin{array}{l}\text { movement. The Arduino board and digital potentiometer will be integrate by } \\
\text { connecting both pins in between wiper, W pin and ground, GND to the DB9 }\end{array}$ \\
\hline Keywords: & $\begin{array}{l}\text { pins of remote control platform, which is TX and RX pins respectively. } \\
\text { Humanoid robot as known as TOMY i-SOBOT is use as a preferred model }\end{array}$ \\
\hline Arduino & due to wide usage in many applications. A digital potentiometer will be \\
\hline Graphical user interface (GUI) & $\begin{array}{l}\text { transmitted the voltage and current value depend on the digital level through } \\
\text { serial communication to give the instruction for humanoid robot movement. }\end{array}$ \\
\hline Humanoid robot & The humanoid movement based on Guided User Interface (GUI) where the \\
\hline Potentiometers & $\begin{array}{l}\text { user give a commands by pressing the button on the GUI such as turn left, } \\
\text { right, forward, and reverse. The results show that the humanoid movement } \\
\text { able to control based on the voltage and current in a digital } \\
\text { potentiometers value. }\end{array}$ \\
\hline
\end{tabular}

Copyright $@ 2019$ Institute of Advanced Engineering and Science. All rights reserved.

\section{Corresponding Author:}

Hairol Nizam Mohd Shah,

Center for Robotics and Industrial Automation,

Faculty of Electrical Engineering,

Universiti Teknikal Malaysia Melaka, Malaysia.

Email: hnizam@utem.edu.my

\section{INTRODUCTION}

Nowadays, there is more variety of remote control types that has been developed for variant purposes, for example, radio-controlled for toys, industrial automation, temperature and heat controller, gaming consoles or joy pads for visual simulation, and even purpose for fixed range devices such as car key remote. Remote control transmitter is a medium to transmit the electrical signal to the model receiver in order to move it. The common design for remote enable it to operate by using several buttons or keypads located at the platform of the remote control. Some of this controller can also operate by using personal computer (PC) or laptop with similar performances and monitor display to indicate the condition of controlled models.

Remote control system is more varied to many applications such as PC control, industries, military purposes, gaming consoles, as well as home appliances. The problem occurred when the programmed robot can only move within the designated area, which the movements are commonly limited to a certain range of workspaces. Somehow, the movements of robot after hex code is programmed and compiled are not exactly the same with the supposed direction.

The remote controller transmitter usually communicates with the platform receiver via two-way communications where the data consists of instructions were transmitted to the receiver for data analysis. 
Thus, desired controller need to be integrated with modular devices to enable humanoid to receive any information from transmitter. User interface for remote indicates as a platform for PC to observe the movement direction for humanoid whenever the button pressed according to the desired direction. As a matter of fact, the development of PC-based remote controller gives more advantages than usual remote control that enables humanoid robot to control movements at long range without requiring user to move to another location.

The main reason for replacing joystick potentiometer into digital potentiometer is because of the smaller size, easier and accurately set, controllable remotely, and cost effective. Digital potentiometers are suitable for integration into electrical/electronic environments since the switching elements can be implemented at least substantially using only electronic/electrical technologies. Digital potentiometers can be implemented in digital-to-analog converters (DAC) as replacements for mechanical potentiometers and rheostats. Non-volatile programmable digital potentiometers have been used in LCD (liquid crystal display) screen adjustment, volume control, automated product calibration, remote adjustment of equipment, signal processing and other applications requiring the replacement of mechanical potentiometers.

The elements of motivation occurred behind this project is based on the purpose for remote control transmitter in many applications. The controller configuration must be simple, user friendly, easy to understand and able to move the humanoid from a long range position. More or less, the configuration similar to a gaming console that can move on models into desired ways without encountering any difficulties such as lagging, low sensitivity of turning motion, unsynchronized controller for humanoid motion and high possibility for the model to collide the obstacles when it is not working properly.

\section{RESEARCH METHOD}

Haeil Hyun et al [1] was introduced the developed and implementation remote control by using mobile phones to control PC applications. Mobile phones have a numbers of advantages as well as wide network coverage as well as it is portable-to-use at any place. The remote control system overview is shown in Figure 1 where it contains mobile phone and PC control system. This kind of controllers implementation on specific designed in remote control car was discussed by Wen Qu and Ting Zhu [2]. There are few disadvantages in mobile phones for example battery life, storage capacity and memory. The time delay for mobile phone is a major difficulty in wireless communication, where time delay is due to encoding and digital error correction encoding.

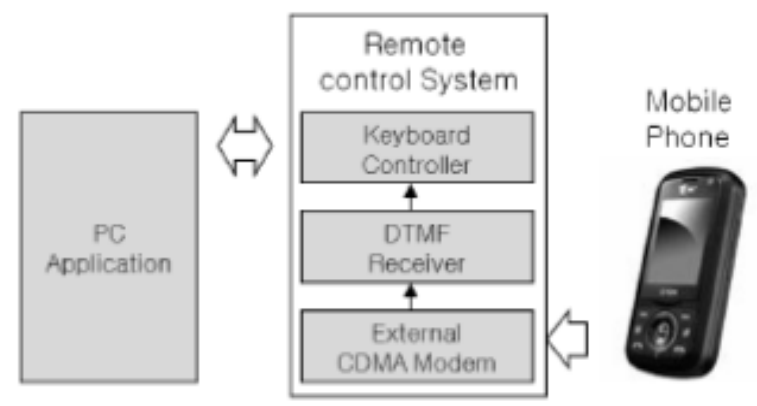

Figure 1. Remote control system for PC application via mobile phone

Bao XiLin and Wu Min [3] was report about PC based remote control system on microcontroller unit (MCU). The main purpose of this design is to improve PC control equipment and suitable for multimedia applications as well as gain benefits for academicians for multimedia-based pedagogy. The remote control will be connected with a PC and MCU via RS-232 serial port. The user can fixed the operation for desired controller to achieve PC operation different requirements, resolve difficulties for uncustomized PC control function. The implementation of computer remote control provides a great convenience for users to operate.

Young-Duk Kim et al. [4], adapts the application of remote control with their design and implement of user friendly remote controllers specialized for emergency tasks. There are two types of proposed controllers with their own features. The first type uses handheld, touch screen based type controller called UMPC (Ultra Mobile Personal Computer) based platform that is lightweight and portable for fire fighters while the other one implement joystick based controller with high accuracy and rapid controls for specific 
tasks in risky environment, as shown in Figure 2. Both type use different wireless communication channels for both control messages exchanges and video data processing. The comparison between two recommended controllers in terms of functional features is quite similar except that the GUI (Graphical User Interface) components for joystick-type.

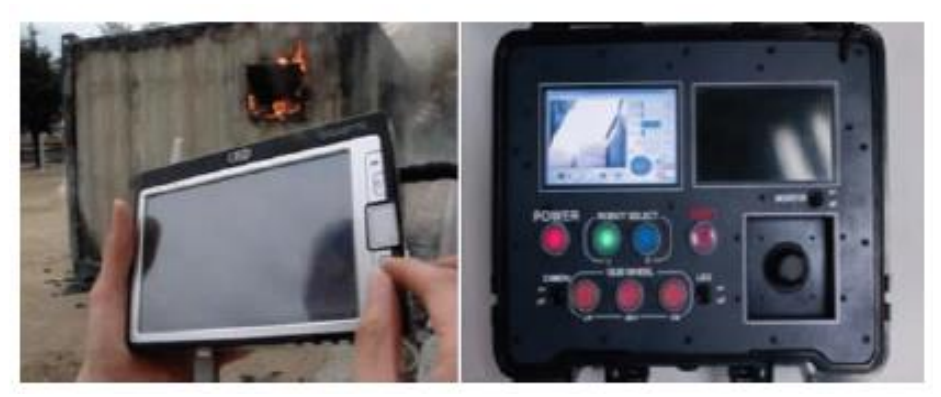

Figure 2. UMPC based (left) and Joystick based remote controller (right)

Wang Shaokun et. al [5] was proposed the ARM9 based on wireless remote control car system design scheme. The system was implemented with ARM9 processor architecture and adopts Linux operating system as the embedded operating system. The efficiency of hardware resources increased by operating system task scheduling using the embedded application software to make up for lack of hardware resources. The system introduces a few of software tools directly to the mobile robot system to complete the complex intelligent control and decision making tasks. The maximum performance of hardware resources can be exploited to ensure the stability of mobile robots with real-time. Based on the system overview for wireless remote control car in Figure 3, the system can divided into three parts consisting embedded remote control car, wireless network equipment and PC console.

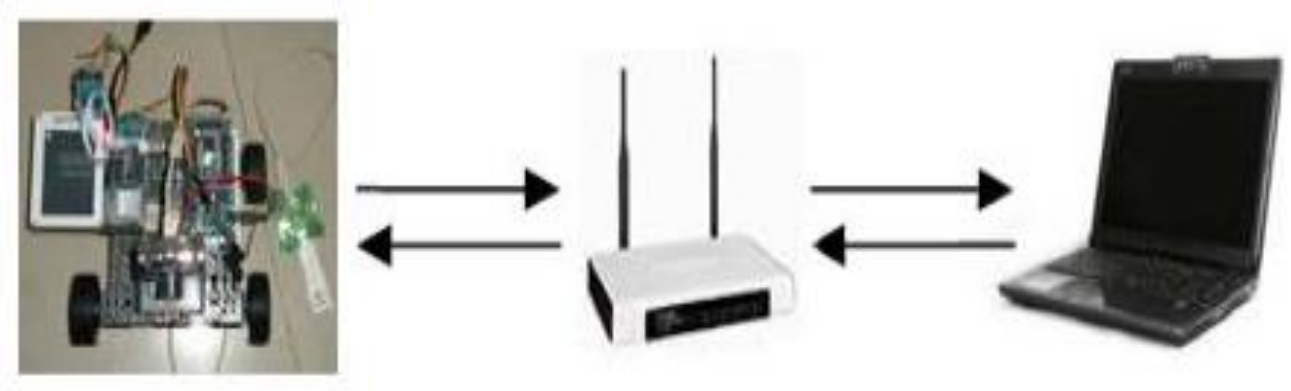

Figure 3. ARM9 wireless remote control overview

The autonomous-robot was proposed by Gow Moh Kee et al. [6] using controller board with PIC16F877A. There are 5 input/output (I/O) ports with 33 pins available for different ports. It only uses flash read-only memory for program storage so it can be reprogrammable and do not required ultraviolet light source to erase the program every time new program is uploaded. The development of autonomous robot is divided into two main sections namely as the electronics design and mechanical design. The vital component of this robot is the PIC 16F877A microcontroller can be programmed using the PicBasic Pro compiler. The robot is equipped with the obstacle avoidance ability implements by the infrared sensors. This robot also capable to play pre-recorded messages is stored in the Winbond ISD 2560 Chipcorder. Figure 4 shows an example of autonomous robots operated by PIC. 


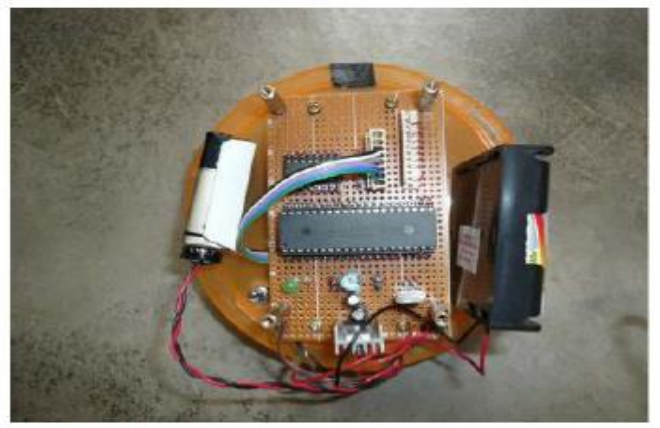

Figure 4. Autonomous robot controller board

Guoxin Luo [7] was discussed the states about integration between RS232 interface with Zigbee module for wireless transmission purposes. The medium for RS232 signal into wireless signal converter was introduced with the embedded MAX232 for RS232 interface with ZigBee module connections and CC2430 program with internal C51 for wireless communication. The usage of RS232 interfaces is widespread in many data transmission applications. The paper also stressed out about technical requirements for wireless module, states that Zigbee transmitter and receiver can send and receive correct data respectively, the effective transmission range and the output power can be controlled by algorithm without any disturbances. The serial interface level conversion circuit realizes the conversion by SP3223E with a standard 9 pins serial interface provided.

\section{RESEARCH METHODOLOGY}

The project methodology takes into consideration the main stream of activities that will take place from beginning of project stage until completion. The critical part of activities involves developing and integrating Arduino module and PC remote control $[8,9]$.

\subsection{Digital Potentiometer}

The digital potentiometer features are capable to adjust the resistance value to produce the voltage output in digital signals [10]. The structure is commonly used for digital potentiometers that can exceed to 256 steps which is 8-bit resolution. If the potentiometer is above 256 steps, it can be high efficiency to use a more complex segmented structure.

\subsection{Measuring Voltage Divider}

A voltage divider is a simple circuit to increases or decreased a voltage from larger to smaller or vice versa. The circuit will be implemented using two series resistors and an input voltage than the output voltage based on the fraction of the reference voltage (VR). The resistor arrays of R1, R2, and R3, are illustrated in Figure 5. Therefore, the output voltage will be calculated by using (1) and (2).

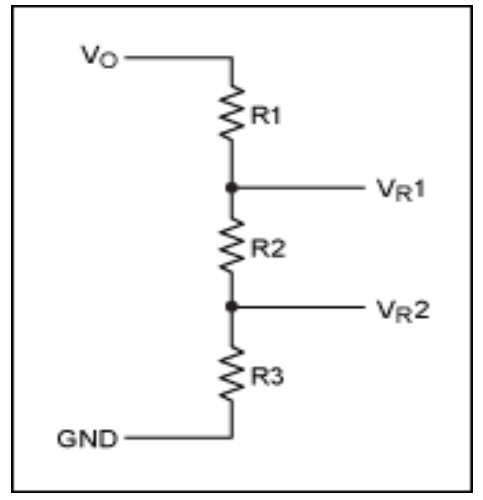

Figure 5. Resistor array 


$$
\begin{aligned}
& R_{T}=R_{1}+R_{2}+R_{3} \\
& V_{\text {out }}=\left(\frac{R_{2}}{R_{T}}\right) \times V_{R}
\end{aligned}
$$

\subsection{Wiper Resistance Calculations}

The digital potentiometer is used to control the voltage values in terms of digital environment. Either to produce low or high voltage depends on the internal resistances embedded inside the mini chip. The internal resistance is called wiper resistance known as adjustable resistor can allow or prevent high number of voltages into circuits. The MCP4151 digital potentiometer have a sensitivity of 8 - bit can produced 256 taps for each potentiometer. The nominal resistance normally stated as $\mathrm{RAB}=100 \mathrm{k} \Omega$ and the wiper resistance $\mathrm{RW}=125 \Omega$. By assume Dn value to 222 . The resistance in between wiper with Terminal $\mathrm{A}$ and $\mathrm{B}$ can be obtained in (3) and (4) respectively.

$$
\begin{aligned}
& R_{W A}\left(D_{n}\right)=\frac{\left(R_{A B}\right)\left(256-D_{n}\right)}{256}+R_{W} \\
& R_{W B}\left(D_{n}\right)=\frac{\left(R_{A B}\right)\left(D_{n}\right)}{256}+R_{W}
\end{aligned}
$$

\subsection{Analog to Digital Conversion}

Since microcontrollers only able to read the digital value, the potentiometer voltage needs to be converted into digital value [11]. The amount of steps available determines the resolution of the digital potentiometer. The digital potentiometer step is quite similar to analog-to-digital converter (ADC) for microcontrollers [12-13]. For example, the number of bits for digital potentiometer MCP 4151 is 8-bits resolution. The 8-bits resolution quantization level for the potentiometer can be calculated using in 5 .

$$
\text { Quantization level, } N=2^{M}-1
$$

Thus, the microcontroller value range only valid from 0 to 1024. The voltage resolution of an ADC equals to the maximum scale voltage divided by the size steps of bits number. Since most of the microcontrollers have a maximum $5 \mathrm{~V}$ supply, the value will be fixed as maximum scale or reference voltage, Vref $=5 \mathrm{~V}$. Voltage resolution can be determine by using (6).

$$
\text { Voltage resolution, } Q=\frac{V_{r e f}}{N}
$$

Therefore, to determine the digital voltage produced by digital potentiometers, (7) will be applied after the reference or input voltage obtained.

$$
\text { Digital output, } D=\frac{V_{\text {in }}}{Q}
$$

\subsection{Digital Potentiometer Setup}

To construct the hardware setup, the first step is to determine the pins location of digital potentiometer to connect with prescribed output. The Arduino and digital potentiometer will be integrated by connecting both pins in between wiper, W pin and ground, GND to the DB9 pins of remote control platform, which is TX and RX pins respectively. Figure 6 indicates the integration between Arduino and digital potentiometer with the original remote platform. 


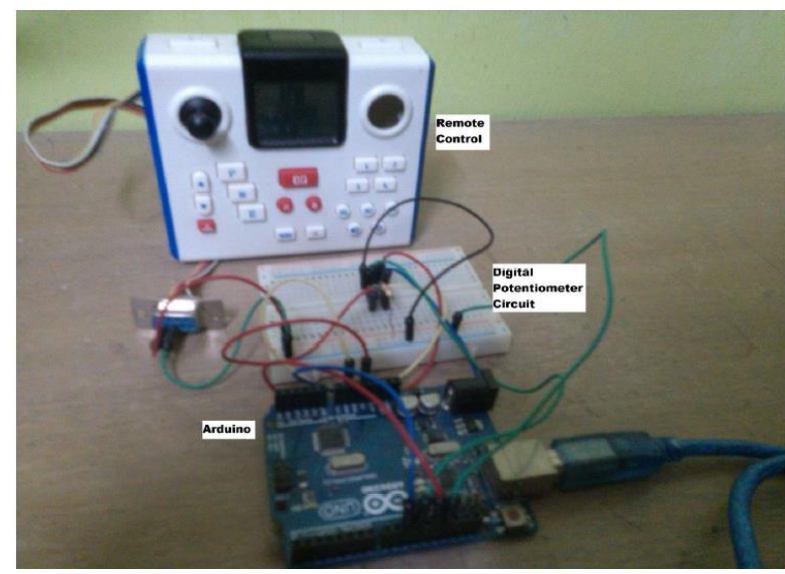

Figure 6. Integrated circuit with remote control platform

\section{RESULTS}

To verify the variable potentiometer, three experiments that have been conducted related with digital potentiometer and variable potentiometer.

\subsection{Digital and Variable Potentiometer for Voltage and Current Value Measurements}

The parameter values of digital and variable potentiometer circuit design have been measured using a multimeter to obtain the voltage and current value. By using a blue LED as an indicator, the process to measure the voltage and current value will be proceeded. The average measured value for both parameters will be determined based on three repetition number of tests. Table 1 and Table 2 gives the data collected for measuring voltage and current for digital level.

Table 1. LED Measured for Digital Potentiometer Level

\begin{tabular}{|c|c|c|c|c|}
\hline Parameter & \multicolumn{4}{|c|}{ Measured voltage (V) } \\
\hline $\begin{array}{c}\text { Digital } \\
\text { Level }\end{array}$ & 1 & 2 & 3 & Avg \\
\hline 250 & 2.84 & 2.84 & 2.84 & 2.84 \\
\hline 200 & 2.63 & 2.63 & 2.63 & 2.63 \\
\hline 150 & 2.53 & 2.53 & 2.53 & 2.53 \\
\hline 100 & 1.971 & 1.971 & 1.971 & 1.971 \\
\hline 50 & 0.994 & 0.994 & 0.994 & 0.994 \\
\hline 0 & 0.0247 & 0.0247 & 0.0247 & 0.0247 \\
\hline
\end{tabular}

(a) Voltage

\begin{tabular}{|c|c|c|c|c|}
\hline Parameter & \multicolumn{4}{|c|}{ Measured current (mA) } \\
\hline $\begin{array}{c}\text { Digital } \\
\text { Level }\end{array}$ & 1 & 2 & 3 & Avg \\
\hline 250 & 8.37 & 8.42 & 8.43 & 8.407 \\
\hline 200 & 1.87 & 1.87 & 1.88 & 1.873 \\
\hline 150 & 1.03 & 1.03 & 1.04 & 1.033 \\
\hline 100 & 0.7 & 0.7 & 0.69 & 0.697 \\
\hline 50 & 0.5 & 0.5 & 0.51 & 0.503 \\
\hline 0 & 0.07 & 0.07 & 0.07 & 0.07 \\
\hline
\end{tabular}

(b) Current

Table 2. Measured for Variable Potentiometer Direction

\begin{tabular}{|c|c|c|c|c|}
\hline \multirow{2}{*}{ Direction } & \multicolumn{4}{|c|}{ Measured voltage (V) } \\
\cline { 2 - 5 } & 1 & 2 & 3 & Avg \\
\hline Up & 3.28 & 3.3 & 3.31 & 3.3 \\
\hline Down & 0.0092 & 0.0096 & 0.0072 & 0.0086 \\
\hline Left & 2.03 & 2.03 & 2.03 & 2.03 \\
\hline Right & 2.03 & 2.03 & 2.03 & 2.03 \\
\hline
\end{tabular}

(a) Voltage

\begin{tabular}{|c|c|c|c|c|}
\hline \multirow{2}{*}{ Direction } & \multicolumn{4}{|c|}{ Measured current (mA) } \\
\cline { 2 - 5 } & 1 & 2 & 3 & Avg \\
\hline Up & 127.4 & 126.5 & 125.7 & 126.5 \\
\hline Down & 0.05 & 0.06 & 0.06 & 0.057 \\
\hline Left & 0.86 & 0.86 & 0.86 & 0.86 \\
\hline Right & 0.86 & 0.86 & 0.86 & 0.86 \\
\hline
\end{tabular}

(b) Current 


\subsection{Digital Potentiometer Level Direction}

In this experiment, a blue LED will be replaced to remote control as an indicator to determine the direction of humanoid robot based on the digital potentiometer level. The voltage and current obtained from the digital potentiometer level will determine the robot direction from the LCD remote platform. Table 1 give the data for voltage and current measuring value for digital potentiometer level respectively. The LCD remote platform indicates the direction based on the arrow at the screen. Thus the range of level for the desired direction is based on the digital potentiometer level as shown in Table 3.

Therefore, the ranges for digital level in terms of direction are stated as:

Forward range; $160<$ Dforward $<255$

Stop range; $50<$ Dstop $<150$

Backward range; $0<$ Dbackward $<50$

In Table 2 show that, the maximum voltage and current obtain is $2.827 \mathrm{~V}$ and $8.63 \mathrm{~mA}$, while the minimum voltage and current obtain is $0.34 \mathrm{~V}$ and $0.86 \mathrm{~mA}$ respectively. Meanwhile the range of value for backward direction counts from level 0 to 50 where the range of current and voltage is from $0.86 \mathrm{~mA}$ to 1.31 $\mathrm{mA}$ and $0.34 \mathrm{~V}$ to $1.454 \mathrm{~V}$. The stop condition was count from level 60 to 150 which obtained the range of current and voltage is $1.31 \mathrm{~mA}$ to $1.82 \mathrm{~mA}$ and $1.45 \mathrm{~V}$ to $2.33 \mathrm{~V}$. Finally, the forward direction in level 160 to 250 , the range of current and voltage is $1.82 \mathrm{~mA}$ to $8.63 \mathrm{~mA}$ and $2.33 \mathrm{~V}$ to $2.83 \mathrm{~V}$ respectively.

\subsection{Time Interval for Digital Potentiometer Direction}

To verify the relation between digital potentiometer levels with the time interval, the time interval where the humanoid robot reaches the destination point with different length will be collected within range 0.5, 07 and 1.0 meter at each digital potentiometer level. There are two types of direction that has been measured, which is forward and backward direction. The data obtained according to the range of digital level that indicates the direction of the humanoid robot itself. Table 3 to 6 provides the data collected for time interval for both directions at length $0.5,0.7$ and 1.0 meter respectively.

Table 3. Remote Control Measured for Digital Potentiometer Level

\begin{tabular}{|c|c|c|c|c|}
\hline Parameter & \multicolumn{4}{|c|}{ Measured voltage (V) } \\
\hline $\begin{array}{c}\text { Digipot } \\
\text { Level }\end{array}$ & 1 & 2 & 3 & Avg \\
\hline 250 & 2.8 & 2.85 & 2.83 & 2.827 \\
\hline 200 & 2.56 & 2.59 & 2.57 & 2.573 \\
\hline 150 & 2.36 & 2.31 & 2.33 & 2.333 \\
\hline 100 & 1.96 & 1.97 & 1.985 & 1.972 \\
\hline 50 & 1.444 & 1.452 & 1.465 & 1.454 \\
\hline 0 & 0.296 & 0.4 & 0.323 & 0.34 \\
\hline
\end{tabular}

(a) Voltage

\begin{tabular}{|c|c|c|c|c|}
\hline Parameter & \multicolumn{4}{|c|}{ Measured current (mA) } \\
\hline $\begin{array}{c}\text { Digipot } \\
\text { Level }\end{array}$ & 1 & 2 & 3 & Avg \\
\hline 250 & 8.64 & 8.6 & 8.65 & 8.63 \\
\hline 200 & 2.64 & 2.63 & 2.62 & 2.63 \\
\hline 150 & 1.83 & 1.82 & 1.81 & 1.82 \\
\hline 100 & 1.51 & 1.5 & 1.5 & 1.503 \\
\hline 50 & 1.31 & 1.31 & 1.31 & 1.31 \\
\hline 0 & 0.86 & 0.85 & 0.87 & 0.86 \\
\hline
\end{tabular}

(b) Current

Table 4. Digital Potentiometer Level with Direction

\begin{tabular}{|c|c|}
\hline $\begin{array}{c}\text { Digipot } \\
\text { Level }\end{array}$ & Direction \\
\hline 250 & Forward \\
\hline 200 & Forward \\
\hline 150 & Stop \\
\hline 100 & Stop \\
\hline 50 & Backward \\
\hline 0 & Backward \\
\hline
\end{tabular}


Table 5. Time Interval at Length for Forward

\begin{tabular}{|c|c|c|c|c|}
\hline Parameter & \multicolumn{4}{|c|}{ Time interval at $0.5 \mathrm{~m}(\mathrm{~s})$} \\
\hline $\begin{array}{c}\text { Digital } \\
\text { Level }\end{array}$ & 1 & 2 & 3 & Avg \\
\hline 250 & 22.28 & 21.97 & 22.55 & 22.36 \\
\hline 240 & 22.41 & 22.52 & 22.84 & 22.59 \\
\hline 230 & 22.67 & 23.22 & 23.32 & 23.07 \\
\hline 220 & 23.38 & 23.45 & 23.48 & 23.44 \\
\hline 210 & 23.81 & 23.88 & 23.69 & 23.79 \\
\hline 200 & 23.96 & 24.32 & 23.96 & 24.08 \\
\hline 190 & 24.32 & 24.4 & 24.22 & 24.31 \\
\hline 180 & 24.64 & 24.44 & 24.75 & 24.61 \\
\hline 170 & 25.1 & 24.85 & 25.25 & 25.07 \\
\hline 160 & 25.55 & 26.05 & 25.8 & 25.47 \\
\hline & & & &
\end{tabular}

(a) $0.5 \mathrm{~m}$

\begin{tabular}{|c|c|c|c|c|}
\hline Parameter & \multicolumn{4}{|c|}{ Time interval at $0.7 \mathrm{~m}(\mathrm{~s})$} \\
\hline $\begin{array}{c}\text { Digital } \\
\text { Level }\end{array}$ & 1 & 2 & 3 & Avg \\
\hline 250 & 31.78 & 31.75 & 31.67 & 31.73 \\
\hline 240 & 31.94 & 31.82 & 32.2 & 31.99 \\
\hline 230 & 32.36 & 32.22 & 32.46 & 32.35 \\
\hline 220 & 32.38 & 32.39 & 32.56 & 32.44 \\
\hline 210 & 32.66 & 32.44 & 32.76 & 32.62 \\
\hline 200 & 32.78 & 32.89 & 33.03 & 32.9 \\
\hline 190 & 32.98 & 33.06 & 33.13 & 33.06 \\
\hline 180 & 33.22 & 33.2 & 33.3 & 33.24 \\
\hline 170 & 33.3 & 33.26 & 33.63 & 33.4 \\
\hline 160 & 33.46 & 33.33 & 34.33 & 33.7 \\
\hline
\end{tabular}

(b) $0.7 \mathrm{~m}$

\begin{tabular}{|c|c|c|c|c|}
\hline Parameter & \multicolumn{4}{|c|}{ Time interval at $1.0 \mathrm{~m}(\mathrm{~s})$} \\
\hline $\begin{array}{c}\text { Digital } \\
\text { Level }\end{array}$ & 1 & 2 & 3 & Avg \\
\hline 250 & 40.43 & 40.65 & 40.56 & 40.55 \\
\hline 240 & 41.13 & 41.38 & 41.23 & 41.25 \\
\hline 230 & 41.67 & 41.74 & 41.55 & 41.65 \\
\hline 220 & 42.12 & 42.24 & 41.95 & 42.1 \\
\hline 210 & 42.42 & 42.63 & 42.55 & 42.53 \\
\hline 200 & 42.75 & 42.85 & 42.88 & 42.83 \\
\hline 190 & 43.05 & 43.11 & 43.27 & 43.14 \\
\hline 180 & 43.34 & 43.54 & 43.43 & 43.44 \\
\hline 170 & 43.79 & 43.86 & 43.98 & 43.88 \\
\hline 160 & 44.21 & 44.14 & 44.28 & 44.21 \\
\hline
\end{tabular}

(c) $1.0 \mathrm{~m}$

Table 6. Time Interval at Length for Backward

\begin{tabular}{|c|c|c|c|c|}
\hline Parameter & \multicolumn{4}{|c|}{ Time interval at $0.5 \mathrm{~m}(\mathrm{~s})$} \\
\hline $\begin{array}{c}\text { Digital } \\
\text { Level }\end{array}$ & 1 & 2 & 3 & Avg \\
\hline 50 & 34.66 & 34.88 & 35.23 & 34.93 \\
\hline 40 & 33.86 & 34.23 & 34.44 & 34.18 \\
\hline 30 & 33.27 & 33.5 & 34.12 & 33.65 \\
\hline 20 & 32.3 & 33.15 & 33.3 & 32.92 \\
\hline 10 & 30.68 & 31.88 & 31.55 & 31.37 \\
\hline 0 & 30.38 & 31.17 & 31.1 & 30.88 \\
\hline
\end{tabular}

\begin{tabular}{|c|c|c|c|c|}
\hline Parameter & \multicolumn{4}{|c|}{ Time interval at $0.7 \mathrm{~m}(\mathrm{~s})$} \\
\hline $\begin{array}{c}\text { Digital } \\
\text { Level }\end{array}$ & 1 & 2 & 3 & Avg \\
\hline 50 & 44.44 & 44.32 & 44.22 & 44.33 \\
\hline 40 & 44.05 & 43.36 & 43.46 & 43.62 \\
\hline 30 & 43.35 & 43.15 & 43.12 & 43.21 \\
\hline 20 & 42.31 & 42.23 & 42.21 & 42.25 \\
\hline 10 & 41.84 & 41.88 & 41.92 & 41.88 \\
\hline 0 & 41.7 & 41.82 & 41.74 & 41.75 \\
\hline
\end{tabular}

\begin{tabular}{|c|c|c|c|c|}
\hline Parameter & \multicolumn{4}{|c|}{ Time interval at $1.0 \mathrm{~m}(\mathrm{~s})$} \\
\hline $\begin{array}{c}\text { Digital } \\
\text { Level }\end{array}$ & 1 & 2 & 3 & Avg \\
\hline 50 & 54.67 & 54.54 & 54.47 & 54.56 \\
\hline 40 & 54.3 & 54.11 & 54.04 & 54.13 \\
\hline 30 & 53.43 & 53.53 & 53.62 & 53.53 \\
\hline 20 & 53.14 & 53.2 & 53.24 & 53.19 \\
\hline 10 & 52.73 & 52.78 & 52.89 & 52.8 \\
\hline 0 & 52.35 & 52.65 & 52.73 & 52.58 \\
\hline
\end{tabular}

\section{CONCLUSION}

As conclusion, this paper introduced the developed a digital potentiometer circuit board that able to control the humanoid robot movement by using implement the digital potentiometer features to the circuit board integrated with the humanoid robot remote control. The humanoid robot able to move using PC with four basic directions which is forward, reverse, right and left. The hardware integration will be tested to verify the functionality and connectivity with the humanoid robot remote control where its enable to communicate between the integrated hardware and the humanoid remote control transmitter-receiver. In addition, the data obtained from the result can be used to determine the valid directions for humanoid robot with classify the range for voltage and current respectively.

\section{ACKNOWLEDGEMENTS}

The authors are grateful for the support granted by by Center for Robotics and Industrial Automation, Universiti Teknikal Malaysia Melaka (UTeM) in conducting this research through grant PJP/2018/FKE(4C)/S01605 and Ministry of Higher Education.

\section{REFERENCES}

[1] H. Hyun, J. Park, Y. Cho, and J. W. Jeon, "PC Application Remote Control via Mobile Phone,” pp. 2290-2294, 2010.

[2] W. Qu and T. Zhu, "Remote control of model car by using mobile technology," 2011 IEEE 3rd Int. Conf. Commun. Softw. Networks, pp. 188-191, May 2011.

[3] B. Xilin and W. Min, "Design of Remote Control System for PC Based on MCU," 2012.

[4] Y. Kim, "Design and implementation of user-friendly remote controllers for rescue robots used at fire sites," 2010 IEEE/RSJ Int. Conf. Intell. Robot. Syst., pp. 377-382, Oct. 2010.

[5] W. Shaokun, X. Xiao, and Z. Hongwei, "The Wireless Remote Control Car System Based on ARM9," 2011 First Int. Conf. Instrumentation, Meas. Comput. Commun. Control, pp. 887-890, Oct. 2011. 
[6] G. M. Kee, Z. M. Zain, and R. H. Salimin, "Design and Development PIC-Based Autonomous Robot,” 2008 IEEE Conf. Robot. Autom. Mechatronics, 2008.

[7] G. L. G. Luo, "Wireless transmission of RS232 interface signal based on ZigBee," Anti-Counterfeiting Secur. Identif. Commun. (ASID), 2010 Int. Conf., pp. 239-241, 2010.

[8] H. A Kasdirin, MH Jamaluddin, A. Zaki A and HNM Shah, "Design and Development of a PC-Based Wireles Controller for a Flying Robot Applications", Malaysian Technical Universities Conference on Engineering and Technology, 2009.

[9] HNM Shah, MZA Rashid Z Kamis, MSM Aras, NM Ali, F Wasbari and MNFA Bakar, "Design and Develop an Autonomous UAV Airship for Indoor Surveillance and Monitoring Applications", JOIV: International Journal on Informatics Visualization, 2(1), pp. 1-7, 2018.

[10] HNM Shah, MZA Rashid, MF Abdollah, MN Kamarudin, KL Chow and Z Kamis, "Biometric voice recognition in security system", Indian Journal of Science and Technology, 7(2), pp. 104-112, 2014.

[11] HNM Shah, MZA Rashid and TY Tam, "Develop and Implementation of Autonomous Vision Based Mobile Robot Following Human", International Journal of Advanced Science and Technology, 51, pp. 81-91, 2013.

[12] HNM Shah, MZA Rashid Z Kamis, MSM Aras, NM Ali, F Wasbari and TMMT Anuar, "Sign Detection Vision Based Mobile Robot Platform", Indonesian Journal of Electrical Engineering and Computer Science (IJEECS), 7(2), pp. 524-532, 2017.

[13] HNM Shah, MZA Rashid, Z Kamis, MN Kamarudin, MF Abdollah and A Khamis, "Implementation of Object Recognition Based on Type of Vehicle Entering Main Gate", Indonesian Journal of Electrical Engineering and Computer Science (IJEECS), 3(2), pp. 458-467, 2016. 